\title{
Synthesis, Characterization and Antioxidant Studies of Quinazolin Derivatives
}

\author{
KHALIDA AL-AZAWI \\ Department of Chemistry, College of Science, University of Technology, Baghdad, Iraq. \\ ${ }^{*}$ Correspondence author E-mail: khalidachemistry@gmail.com \\ http://dx.doi.org/10.13005/ojc/320166 \\ (Received: December 19, 2015; Accepted: February 28, 2016)

\begin{abstract}
3-((4-(dimethylamino)benzylidene)amino)-2-methylquinazolin-4(3H)-one (3), 3-((4hydroxybenzylidene)amino)-2-methylquinazolin-4(3H)-one (4), 2-methyl-3-(pyrrolidin-2-ylideneamino) quinazolin-4(3H)-one (5) and 3,3'-((1,4-phenylenebis(methanylylidene)) bis(azanylylidene))bis(2methylquinazolin-4(3H)-one) (6) derived from 3-amino-2-methylquinazolin-4(3H)-one have been synthesized and characterized by elemental analysis, FT-IR, NMR techniques and screened to establish their potential as antioxidants against 1,1-diphenyl-2-picrylhydrazyl (DPPH) and Nitric oxide (NO) radical scavengers. The results revealed that synthesized compounds (5 and 6) are much higher than common antioxidants ascorbic acid and they showed excellent scavenging capacity against DPPH and Nitric oxide (NO). The synthesized compounds (3 and 4) demonstrated encouraging results comparable with ascorbic acid.
\end{abstract}

Key words: Antioxidant activity; Avenging activities; 1,1-diphenyl-2-picrylhydrazyl; Nitric oxide.

\section{INTRODUCTION}

Recently there has been an interesting in the chemistry of quinazoline-4 $(3 H)$-ones because of their medicinal significance. Many of quinazoline derivatives show antifungal, antimicrobial, bronchodilator, antihi-staminic, anti-inflammatory ${ }^{1}$. Some sulpha drugs of quinazolin-4-ones showed exhibited anti-inflammatory and analgesic activities, angiotensin receptor antagonist, antiherpes, nantitubercular, anti- insecticidal and cardiovascular agent $^{2}$. 4-Aminoquinazolines represent as new classes of drugs, they were found excellent inhibitor to the EGFR (epidermal growth factor receptor) ${ }^{3}$. Studies of scavengers, antioxidants, enzymeinhibitors and anti-bacterials have become enormous research areas in the field of pharmaceutics and pharmaceutical chemistry, without which depreciation of human skin, body, disease, and death rate can't be controlled. The discovery of new and useful drugs for a variety of physiological conditions is the result of such type of research. The role of reactive oxygen species (ROS) is of prime consideration in various diseases because such species oxidize the human cell or body. The protection from such ROS 
species to human body is provided by antioxidants ${ }^{4}$. Radicals have been implicated in the causation of several oxidative damages diseases such as liver chirrhosis, atherosclerosis, cancer, diabetes, ageing. An antioxidant can be defined as any substance that when present at low concentrations compared with those of an oxidizable substrate ${ }^{5}$ can inhibit the oxidation of lipids or other molecules by preventing the initiation or propagation of oxidative chain reactions and can thus prevent or repair the damage done to the body's cells by oxygen ${ }^{6}$. Metal-based antioxidants have gained attention recently for their capacity to protect organisms and cells from damage induced by oxidative stress or scavenge free radicals ${ }^{7}$. It is worth mentioning that the antioxidant activity depends on their reactions with free radicals. luga et al. studied the antioxidant activity of trans-resveratrol toward hydroxyl $(\bullet \mathrm{OH})$ and hydroperoxyl $(\bullet \mathrm{OOH})$ radicals in aqueous simulated media, using density functional theory (DFT) and transition state theory (TST) methods, and they concluded that the reactivity of trans-resveratrol with (i) $\bullet \mathrm{OH}$ radical (in water at physiological $\mathrm{pH}$ ) is mainly governed by a sequential electron proton transfer (SE-ET) mechanism; and with $\bullet \mathrm{OOH}$, it occurs only by phenolic hydrogen abstraction ${ }^{8}$. In another study, Leopoldini et al. found that the addition of $\mathrm{OH}$ radical to caffeic acid is slightly favored with respect to the hydrogen atom transfer, while the single electron transfer is unlikely, since thermodynamically, it is unfavorable ${ }^{9}$. Mayer et al. and Oksana et al. reported that the reactivity of phenols toward free radicals, such as $\mathrm{CH} 3 \mathrm{OO} \cdot$ and $\mathrm{PhO}$, involved a PCET mechanism ${ }^{10,11}$. In this study, we describe the synthesis of quinozoline derivatives (Scheme 1) and we describe their characterization through spectral data (FT-IR, H-NMR) and elemental analysis $(\mathrm{CHN})$ inadition to discuss the in vitro antioxidant activities of the compounds (3-6).

\section{MATERIALS AND METHODS}

\section{Chemicals}

All chemical used as supplied and they were of reagent grade, supplied by Segma-Aldrige and Merck. Melting points were determined on SMP40 melting point apparatus and were uncorrected. The IR spectra of the compounds were recorded on a shimadzu FT-IR-8300 spectrometer as $\mathrm{KBr}$ disks. Elemental micro analysis, was carried out using C.H.N elemental analyzer model 5500-
Carlo Erba instrument. Nuclear magnetic resonance (NMR) spectra were recorded on Bruker specrospin ultra shield magnets $300 \mathrm{MHz}$ instrument using tetramethyl silane (TMS) as an internal standared and DMSO-d6 as a solvent.

Synthesis of 2-methyl-4H-benzo[d][1,3]oxazin-4one (1) and 3-amino-2-methylquinazolin-4(3H)one (2)

The starting materials 2-methyl-4H-benzo[d] [1,3]oxazin-4-one and 3-amino-2-methylquinazolin$4(3 \mathrm{H})$-one (2) were prepared according to a literature method $^{12}$.

\section{Synthesis of the compounds (3-6)}

A mixture of 3-amino-2-methylquinazolin$4(3 \mathrm{H})$-one (2) $(0.005 \mathrm{~mol})$ in ethanol $(50 \mathrm{~mL})$ and appropriate carbonyl compounds $(0.005 \mathrm{~mol})$ with a few drops of acetic acid was reûuxed for 8 hrs. The mixture allowed to cool and ûltered. The separated solid was washed with aqueous water and recrystallized from hot ethanol.

Note: Compound (6); was synthesized in the same method with $(0.01 \mathrm{~mol})$ of 3 -amino-2methylquinazolin-4(3H)-one (2).

3-((4-(dimethylamino)benzylidene)amino)-2methylquinazolin-4(3H)-one (3)

Yield $68 \%$, mp $191-193^{\circ} \mathrm{C}$. FT-IR: 3047.4

for $\mathrm{C}-\mathrm{H}$ aromatic, 1699.6 for carbonyl, $1611.3(\mathrm{C}=\mathrm{N})$. ${ }^{1} \mathrm{H}-\mathrm{NMR} 2.410\left(\mathrm{~s}, 3 \mathrm{H}, \mathrm{CH}_{3}\right), 7.01-7.32(\mathrm{~m}, 1 \mathrm{H}, \mathrm{Ar}-\mathrm{H})$, $8.99(\mathrm{~d}, 1 \mathrm{H}, \mathrm{H}-\mathrm{C}=\mathrm{N})$.). Elemental analysis $(\mathrm{CHN})$; $\mathrm{C}$ : $70.90 \%(70.57 \%) \mathrm{H}: 6.03 \%$ (5.92\%) and N: 18.78 (18.29\%).

\section{3-(4-Hydroxybenzylideneamino)-2-methyl} quinazolin-4-(3H)-one

Yield 72\%, mp 204-206 ${ }^{\circ} \mathrm{C}$. FT-IR: 3189 br for O-H aromatic, 1704.3 for carbonyl, 1609.0 $(\mathrm{C}=\mathrm{N}) .{ }^{1} \mathrm{H}-\mathrm{NMR} 2.37\left(\mathrm{~s}, 3 \mathrm{H}, \mathrm{CH}_{3}\right), 6.84-7.01(\mathrm{~m}$, $1 \mathrm{H}, \operatorname{Ar}-\mathrm{H}), 5.32(\mathrm{~s}, 1 \mathrm{H}, \mathrm{OH}), 9.33(\mathrm{~d}, 1 \mathrm{H}, \mathrm{H}-\mathrm{C}=\mathrm{N})$. Elemental analysis (CHN); C: $69.11 \%(68.81 \%) \mathrm{H}$ : $4.91 \%(4.69 \%)$ and $\mathrm{N}: 14.82(15.05 \%)$.

\section{2-methyl-3-((2-oxoindolin-3-ylidene)amino) quinazolin-4(3H)-one (5)}

Yield $65 \%$, mp $118^{\circ} \mathrm{C}$. FT-IR: $3396.4(\mathrm{~N}-\mathrm{H})$, 3088.1 and 3074.0 for $\mathrm{C}-\mathrm{H}$ aromatic, 1683.1 and 1669.2 for carbonyls, $1620.9(\mathrm{C}=\mathrm{N}) .{ }^{1} \mathrm{H}-\mathrm{NMR} 2.410$ (s, 3H, $\left.\mathrm{CH}_{3}\right), 7.01-7.32(\mathrm{~m}, 1 \mathrm{H}, \mathrm{Ar}-\mathrm{H}), 8.91(\mathrm{~s}, 1 \mathrm{H}$, 


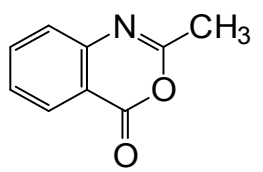

(1)

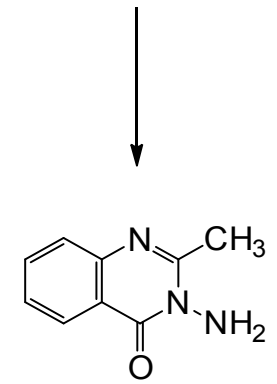

(2)

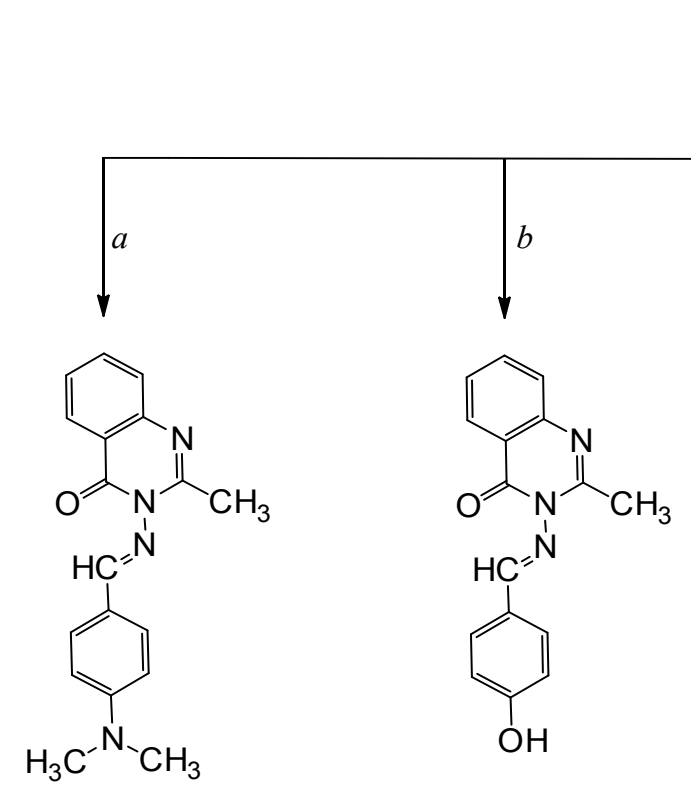

(3)
(4)

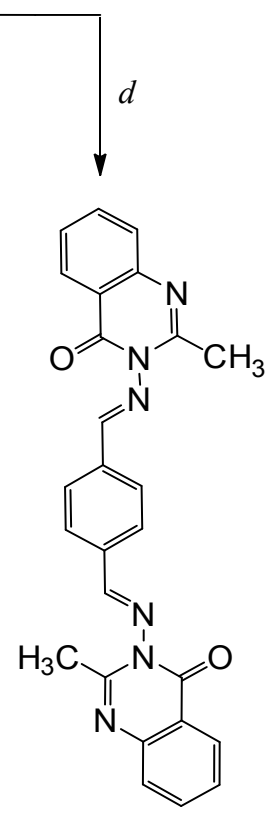

(6)

$a=N, N$-dimethyl-4-aminobenzaldehyde

$b=p$-hydroxybenzaldehyde

$c=$ indoline-2,3-dione

$d=$ terephthalaldehyde 
$\mathrm{NH})$. Elemental analysis (CHN); C: $67.92 \%$ (67.10 \%) $\mathrm{H}: 4.20 \%$ (3.97\%) and $\mathrm{H}: 18.90$ (18.41\%).

3,3'-((1,4-phenylenebis (methanylylidene)) bis(azanylylidene))bis(2-methylquinazolin-4(3H)one) (6)

Yield $59 \%)$, mp $177-181^{\circ} \mathrm{C}$. FT-IR: 3084.1 for $\mathrm{C}-\mathrm{H}$ aromatic, 1679.0 for carbonyl, $1622.5(\mathrm{C}=\mathrm{N})$. ${ }^{1} \mathrm{H}-\mathrm{NMR} 2.62(\mathrm{~s}, 3 \mathrm{H}, \mathrm{CH} 3), 6.77-7.06(\mathrm{~m}, 1 \mathrm{H}, \mathrm{Ar}-\mathrm{H})$, 7.9 (dd, $1 \mathrm{H}, \mathrm{Ar}-\mathrm{H})$. Elemental analysis $(\mathrm{CHN})$; $\mathrm{C}$ $70.21 \%(69.63 \%) \mathrm{H}: 4.83 \%$ (4.49\%) and $\mathrm{N}: 19.11$ (18.74\%).

\section{Antioxidant Activities}

\section{DPPH free radical scavenging assay}

The free radical scavenging activity of the synthesized compounds (3-6) was measured using DPPH by the method of Blios (1958) ${ }^{13}$. A $0.1 \mathrm{mM}$ solution of DPPH in methanol was prepared and $1 \mathrm{ml}$ of this solution was added to $3 \mathrm{ml}$ of various concentrations $0.2,0.3,0.4$ and $0.5 \mathrm{mg} / \mathrm{mL}$. of sample dissolved in methanol to be tested. After $30 \mathrm{~min}$, absorbance was measured at $517 \mathrm{~nm}$. Ascorbic acid was used as a reference material. All measurements were done in triplicates and mean values were calculated. The scavenging activity was calculated as follows

$\%$ inhibition $=\frac{\text { Absorbanse Control }- \text { Absorbanse Sample }}{\text { Absorbanse Control }} \times 100$

\section{Nitric oxide radical scavenging assay}

The method described by Garrat (1964) $)^{14}$ was adopted to determine the nitric oxide radical scavenging activity of compounds (3-6). Sodium nitroprusside $(1 \mathrm{~mL}$ of $10 \mathrm{mM}$ ) prepared in phosphate buffer saline $(\mathrm{pH} \mathrm{7.4)}$ was mixed with 1 $\mathrm{mL}$ of compounds (3-6) at various concentrations ranging from $0.2,0.3,0.4$ and $0.5 \mathrm{mg} / \mathrm{mL}$. The mixture was incubated at $25{ }^{\circ} \mathrm{C}$ for $150 \mathrm{~min}$. To 1 $\mathrm{mL}$ of the incubated solution, $1 \mathrm{~mL}$ of Griess' 1.0 $\mathrm{ml}$ sulfanilic acid reagent $(0.33 \%$ prepared in $20 \%$ glacial acetic acid at room temperature for $5 \mathrm{~min}$ with $1 \mathrm{ml}$ of naphthylethylene diamine dihydrochloride $(0.1 \% \mathrm{w} / \mathrm{v})]$ reagent was added. Ascorbic acid was used as a reference material The mixture was incubated at room temperature for $30 \mathrm{~min}$, followed by the measurement of absorbance at $517 \mathrm{~nm}^{15}$. The inhibition efficiency of nitric oxide radical by the synthesized compounds (3-6) was calculated using the equation 2 . All tests were performed in triplicate.

$$
\% \text { inhibition }=\frac{\text { Absorbanse }_{\text {control }}-\text { Absorbanse }_{\text {Sample }}}{\text { Absorbanse }_{\text {Control }}} \times 100
$$

\section{Statistical Analysis}

Data were calculated as means \pm standard errors of mean. The significance of the relationship between the concentration and percentage inhibition were performed with one-way analysis of variance (ANOVA). Statistical significance was set at $p<0.05$.

\section{RESULTS AND DISCUSSION}

The basic nucleus 2-methyl-4H-benzo[d] $[1,3]$ oxazin-4-one and 3-amino-2-methylquinazolin$4(3 \mathrm{H})$-one were successfully synthesized and characterized by FT-IR, NMR and CHN techniques.

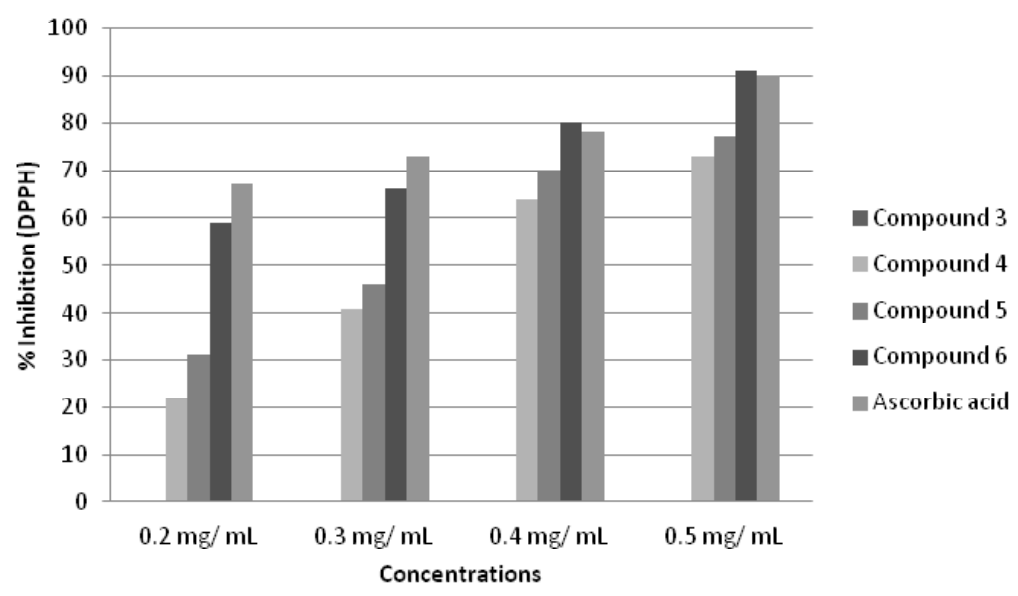

Fig. 1: Effect of compound 3-6 toward DPPH 


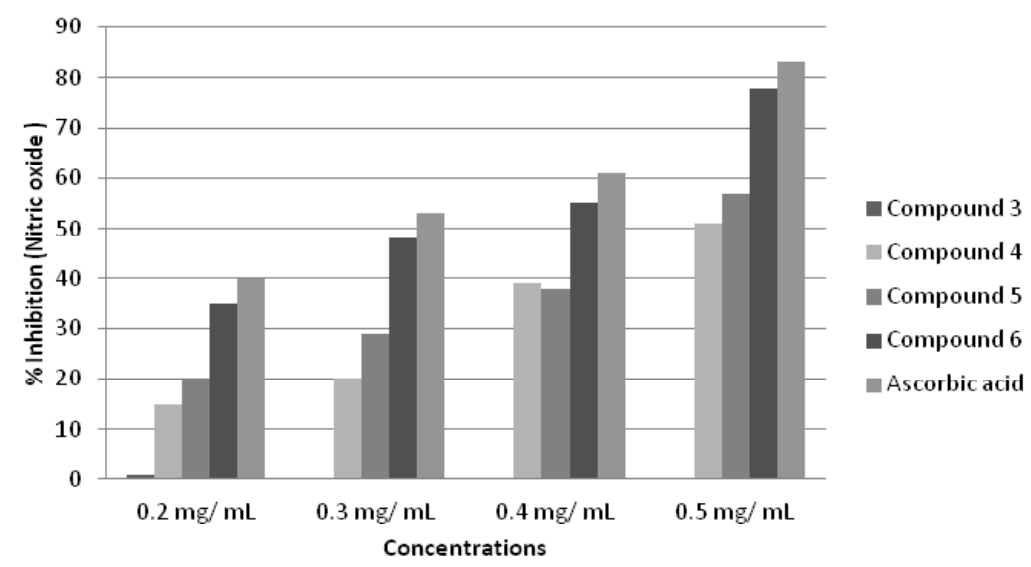

Fig. 2: Effect of compound 3-6 toward Nitric oxide radical

Compound (2) used to synthesis of compounds 3-6, which were confirmed by the absence of $\mathrm{NH}_{2}$ peak in IR spectrum and the presence of $\mathrm{CH}=\mathrm{N}$ peaks at $1611.3,1609.0,1620.9$ and 1622.5 respectively. NMR spectra confirm the formation of compounds 3-6. The structures of the Quinazolin Derivatives (1-6) are shown in Scheme 1. The synthesized compounds (1-6) are coloured powders, stable in air, non-hygroscopic in nature and insoluble in water, but easily soluble in ethanol, acetone, DMF and DMSO.

DPPH is relatively stable nitrogen centered free radical that easily accepts an electron or hydrogen radical to become a stable diamagnetic molecule. It is well documented that reactive oxygen species (ROS) are involved in the etiopathogenesis of numerous chronic diseases such as atherosclerosis, hypertension and coronary heart disease ${ }^{16}$. These free radicals are produced under certain environmental conditions and during normal cellular functions in the body. Antioxidants thus play an important role to protect the human body against damage by reactive oxygen species. The ability of Schiff bases to scavenge free radicals is an important property ${ }^{17}$. In this study, we present the DPPH and Nitric oxide radical scavenging ability of the synthesized Quinazolin Derivatives (1-6). The antioxidant assay was carried out using different concentrations of the test samples, while ascorbic acid (vitamin C) was used as standard. In the DPPH Free radical scavenging activity, compounds (3-6) were evaluated for their free radical scavenging activity with ascorbic acid as standard compound and shown in Figure (1). The scavenging effect increased with the increasing concentrations of test compounds (1-4). From the results of DPPH, It showed that all compounds are equally effective as antioxidant compared to ascorbic acid. DPPH radicals react with suitable reducing agents as a result of which the electrons become paired off forming the corresponding hydrazine. The solution therefore loses color stoicho-metrically depending on the number of electrons taken up. Substances capable of donating electrons/hydrogen atoms are able to convert DPPH (Purple) into their non- radical form 1, 1-diphenyl-2- picrylhydrazine (Yellow), a reaction which can be followed spectrophotometrically.

All the synthesized compounds (3-6) were evaluated for antioxidant activity using nitric oxide method. The nitric oxide assay has been widely used to evaluate the free radical scavenging effectiveness of various antioxidant substances. Nitric oxide generated as a result of decomposition of sodium nitroprusside in aq.medium, interacts with oxygen at physiological $\mathrm{pH}$ to produce nitrite ions, which are measured by using Griess' reagent. The scavenging ability of the synthesized compounds (3-6) was compared with ascorbic acid as a standard. Compounds 5 and 6 produced better scavenging ability as shown in Figure 2. This may be due to the presence of resonance effect and the hetro atoms.

\section{CONCLUSIONS}

The synthesized title compounds 1-6, are characterized by spectral data and evaluate for 
their antioxidant activity. Among the synthesized compounds 5 and 6 , which are having resonance effect and also have hetro atoms exhibiting good activity with maximum scavenging free radical. Therefore, the series has opened new doors for possible modifications of the pharmacophoric replacements of antioxidant and future exploitation.

\section{REFERENCES}

1. Kiruthiga, B.; Kilango, K.; Valentina, P.; Umarani, N. International Journal of PharmTech Research, 2009, 11, 1503-1506, 2009.

2. Bahekar, R.; Rao A.; Ram, R. Ind. J. Heterocycl. Chem., 1999, 8, 225-231.

3. Michel, J.; Cedric, L.; Alexandra, V.; Besson, T. Eur.J.Mid.Chem., 2008, 43,1469-1477.

4. Aslam, M.; Anis, I.; Noreen, Z.; Hussain, A.; Iqbal, L.; Hussain, A.; Kumar, N.; Iqbal, S.; J. Pharm. Sci. Rev. Res., 2015, 32, 148-152

5. Halliwell, B.; Gutteridge, J.M.C. Free Radicals in Biology and Medicine, 3rd ed.; Oxford University Press: New York, NY, USA, 1999, 617-783.

6. Tachakittirungrod, S.; Okonogi, S.; Chowwanapoon-pohn, S. Food Chem. 2007, 103, 381-388.

7. Ejidike, I.; Ajibade, P. Molecules 2015, 20, 9788-9802

8. Iuga, C.; Alvarez-Idaboy, J.R.I.; Russo, N. J. Org. Chem. 2012, 77, 3868-3877.
9. Leopoldini, M.; Chiodo, S.G.; Russo, N.; Toscano, M. J. Chem. Theory Comput. 2011, 7, 4218-4233.

10. Mayer, J.M.; Hrovat, D.A.; Thomas, J.L.; Borden, W.T. J. Am. Chem. Soc. 2002, 124, 11142-11147.

11. Tishchenko, O.; Truhlar, D.G.; Ceulemans, A.; Nguyen, M.T. J. Am. Chem. Soc. 2008, 130, 7000-7010.

12. Sayyed, M.; Mokle, S.; Vibhute, Y. ARKIVOC, 2006, (xI) 221-226

13. Blios, S. Nature. 1958, 26, 1199-1200.

14. Garrat C. Japan. Biochem. Anal. Chem. 1964, 3, 456-458

15. Singleton VL, Orthofer R, Lamuela-Raventos RM. Methods Enzymol. 1999, 299, 152-178.

16. Madhavi, L.; Deshpande, S.; Salunkhe, K. Marcel Dekker: New York, NY, USA, 1996; pp. 1-5.

17. Arulpriya, P.; Lalitha, P.; Hemalatha, S. Der Chem. Sin. 2010, 1, 73-79. 